\title{
Diffuse blastoid B-cell lymphoma: a histologically aggressive variant of $t(14 ; 18)$-negative follicular lymphoma
}

\author{
April Chiu, Glauco Frizzera, Susan Mathew, Elizabeth M Hyjek, Amy Chadburn, \\ Wayne Tam, Daniel M Knowles and Attilio Orazi
}

Department of Pathology and Laboratory Medicine, Weill Medical College of Cornell University,

New York, NY, USA

\begin{abstract}
Among the diffuse lymphomas of B-cell origin, we have encountered one variant displaying blastoid features that morphologically mimic lymphoblastic lymphoma, the blastoid variant of mantle cell lymphoma, and the so-called blastoid transformation of follicular lymphoma. To better characterize this entity, we studied eight cases morphologically, immunohistochemically, and by fluorescence in situ hybridization (FISH) for cytogenetic abnormalities commonly associated with follicular lymphoma and B-cell lymphomas exhibiting high-grade histological features. All eight cases were presented as de novo neoplasms, and displayed an entirely diffuse (five cases) or only minimal follicular (three cases) growth pattern. The neoplastic lymphoid cells were of medium size with round nuclei, fine chromatin, inconspicuous nucleoli, and high mitotic rate; they expressed CD10, BCL6, and BCL2-a phenotype consistent with follicle center cell origin. A proportion of cases expressed MUM1. Their lack of TdT and CYCLIN D1 distinguished them from lymphoblastic lymphoma and the blastoid mantle cell lymphoma, respectively. The neoplastic lymphoid cells consistently expressed CD43 (seven of eight cases) and occasionally other T-cell-associated antigens, including CD5, CD7, CD8, and CD57. Although all cases overexpressed $B C L 2, t(14 ; 18)$ was not detected in any of the five cases examined by FISH; instead, extra copies of chromosome 18 were found in four of five cases. Finally, other cytogenetic abnormalities, including structural abnormalities of $B C L 6$ (allelic loss/gain, rearrangement), monosomy 7, del(13)(q14), and $M Y C$ allelic loss, were frequently detected. The combination of a B-cell CD10 + BCL6 + BCL2 + phenotype in the presence of structural abnormalities of $B C L 6$ is consistent with a follicular center cell derivation for our cases. The lack of $t(14 ; 18)$ seen in our cases, although rare in most cases of follicular lymphoma, has been nevertheless reported in cases of follicular lymphoma with a predominantly diffuse growth pattern. The molecular pathogenesis, clinical manifestations, and prognostic significance of these lesions remain to be elucidated.
\end{abstract}

Modern Pathology (2009) 22, 1507-1517; doi:10.1038/modpathol.2009.106; published online 24 July 2009

Keywords: diffuse blastoid; B cell lymphoma; CD43; chromosome 18; follicular lymphoma

Diffuse lymphomas of B-cell origin represent a heterogeneous group of lymphoid neoplasms. The histologically aggressive subtypes of diffuse B-cell lymphomas include biologically different entities, such as B-lymphoblastic lymphoma/leukemia, Burkitt/ Burkitt-like lymphoma, and diffuse large B-cell lymphoma. They also include subtypes of small

Correspondence: Dr A Orazi, MD, FRCPath(England), Department of Pathology and Laboratory Medicine, Weill Medical College of Cornell University, 525 East 68th Street, Room ST-702-B, New York, NY 10065, USA.

E-mail: ato9002@med.cornell.edu

Received 2 March 2009; revised 18 May 2009; accepted 20 May 2009; published online 24 July 2009
B-cell lymphomas, which display blastoid morphology. The better-described subtypes are the blastoid variant of mantle cell lymphoma and the blastoid transformation of follicular lymphoma. Several of these variants are now recognized in the updated (2008) World Health Organization Classification. ${ }^{1}$

We have identified a group of diffuse B-cell lymphomas characterized by malignant cells that morphologically mimic those seen in blastoid variant of mantle cell lymphoma, blastoid transformation of follicular lymphoma, or B-lymphoblastic leukemia/lymphoma. We report here the clinical, morphological, immunohistochemical, molecular genetic, and cytogenetic findings of eight cases of diffuse B-cell lymphoma with blastoid morphology. 
These neoplasms are associated with a constellation of immunophenotypic and cytogenetic features that suggest that they may represent a distinct subtype within the spectrum of $t(14 ; 18)$-negative follicular lymphoma.

In particular, we investigated the occurrence of cytogenetic events associated with this lymphoma subtype and, alerted by unexpected results of a case observed early in the study, we also evaluated for the presence of aberrant expression of T-cell-associated antigens in this unusual lymphoma subtype.

\section{Materials and methods}

\section{Case Selection}

Eight cases of diffuse blastoid B-cell lymphoma were identified in the consultation and institutional case files of the Division of Hematopathology in the Department of Pathology and Laboratory Medicine at the New York Presbyterian Hospital/Weill Cornell Medical College. Multiple $4-\mu \mathrm{m}$ histological sections were prepared from formalin-fixed, paraffinembedded tissue blocks for routine H\&E evaluation, immunohistochemistry, PCR analysis, and fluorescence in situ hybridization (FISH). IRB approval was obtained for this study.

\section{Immunohistochemical Methods}

Immunohistochemical studies were performed on formalin-fixed, paraffin tissue sections using a TechMate 500 automated immunostainer (Ventana Medical Systems, Tucson, AZ, USA). The staining was performed according to a modified MIP protocol using the ChemMate ABC Peroxidase Secondary Detection System (Ventana Medical Systems) or the Cap-Plus Peroxidase Detection System based on the labeled streptavidin-biotin method (Zymed Laboratories, South San Francisco, CA, USA). Monoclonal and polyclonal antibodies to the following antigens were used for immunophenotyping of the cases: CD2 (AB75), CD4 (1F6), CD5 (4C7), CD7 (CD272), CD10 (56C6), CD16 (2H7), CD21 (2G9), CD23 (1B12), CD56 (CD564) (Novocastra Laboratories, Newcastle upon Tyne, UK); monoclonal rabbit CD3 (SP7), CYCLIN D1 (SP4) (LabVision, Fremont, CA, USA); CD8 (C8/144B), CD20 (L26), BCL2 (124), BCL6 (PGB6), MUM1 (MUM1p) (Dako Cytomation, Carpinteria, CA, USA); CD57 (Leu-7) (BD Biosciences, San Jose, CA, USA); CD43(L60), Pax5(24) (BD Pharmingen, San Diego, CA, USA); TIA-1(26gA10F5) (Coulter Immunotech, Marseille, France); Ki-67(7B11) (Zymed Laboratories); P53(1801) (BioGenex, San Ramon, CA, USA); and polyclonal rabbit anti-TdT (Supertechs, Bethesda, MD, USA). Before staining, the sections were pretreated in a pressure cooker using $10 \mathrm{mM}$ citrate buffer, pH 6.0 (TdT, CD2, CD3, CD4, CD5, CD7, CD10, CD16, CD20, BCL2, BCL6, CD57, Pax-5, Ki-67, and P53), or in a water bath using Dako Target retrieval solution high $\mathrm{pH}$ at $95^{\circ} \mathrm{C}$ for $40 \mathrm{~min}$ (CD56, TIA-1, and CYCLIN D1), or were stained without any pretreatment (CD43). Positive controls of tonsils or thymus (TdT), or nonHodgkin's lymphoma expressing P53, and negative controls with mouse or rabbit IgG were run in parallel. Immunoreactivity was defined as follows: negative $(<10 \%$ positively stained neoplastic lymphoid cells); weakly positive (10-30\% positively stained neoplastic lymphoid cells);or positive ( $>30 \%$ positively stained neoplastic lymphoid cells). Ki-67 results were expressed as the percentage of positively stained nuclei of neoplastic lymphoid cells.

\section{Polymerase Chain Reaction}

PCR was performed on all eight cases of diffuse blastoid B-cell lymphoma using DNA extracted from three $4-\mu \mathrm{m}$ tissue sections prepared from formalinfixed, paraffin-embedded blocks, using the method previously published by Wright and Manos. ${ }^{2}$ Amplification of the immunoglobulin heavy chain gene from both framework 2 and framework 3 part of the $\mathrm{V}$ segment to the $\mathrm{J}$ region was carried out using seminested PCR protocols, as described by Diss et al. ${ }^{3}$ The T-cell receptor gamma (TCR- $\gamma$ ) chain gene was amplified using the method described by McCarthy et al. ${ }^{4}$ After PCR amplification, $10 \mu \mathrm{l}$ of each PCR product was run on $10 \%$ polyacrylamide mini-gels for $1 \mathrm{~h}$ at $125 \mathrm{~V}$, which were then stained with ethidium bromide and viewed under UV light.

\section{Fluorescence In Situ Hybridization}

Interphase FISH analysis was carried out using standard in situ hybridization protocols on paraffin tissue sections from all eight cases. Commercially available probes (Vysis, Downers Grove, IL, USA) used for the detection of chromosomal abnormalities were as follows: LSI IgH (spectrum green)/BCL2 (spectrum orange) dual color, dual fusion translocation probe; LSI BCL6 dual color break apart rearrangement probe (spectrum orange $5^{\prime}$-LSI BCL6 and spectrum green $3^{\prime}$-LSI BCL6); CEP 7 (D7Z1) spectrum green probe; CEP 18 (D1871) spectrum green probe; LSI 13 (13q14) spectrum green probe; and LSI C-MYC (8q24.12-q24.13) spectrum orange probe. At least 100 nuclei, or in most cases 200 nuclei, were scored. A case was considered positive if at least $20 \%$ of the nuclei contained the chromosomal abnormality in question.

\section{Results}

\section{Clinical Features}

The clinical findings are summarized in Table 1. The eight patients ranged in age from 24 to 88 years (median 64.5 years), and included four males and 
Table 1 Clinical features of eight cases of diffuse blastoid B-cell lymphoma

\begin{tabular}{|c|c|c|c|c|c|c|}
\hline Case & $\begin{array}{l}\text { Age (yrs)/ } \\
\text { gender }\end{array}$ & Clinical features & Biopsy site & Stage & Treatment & Outcome \\
\hline 1 & $88 / \mathrm{F}$ & Inguinal LAD, disseminated disease & Inguinal LN & IV & Unknown & Unknown \\
\hline 2 & $67 / F$ & Cervical LAD, pleural effusion & Cervical LN & III & CHOP & Alive, in CR 10 months \\
\hline 3 & $24 / \mathrm{M}$ & Cervical LAD & Cervical LN & I & Unknown & Unknown \\
\hline 4 & $64 / \mathrm{M}$ & $\begin{array}{l}\text { Cervical and mediastinal LAD, } \\
\text { subclavian } \\
\text { vein thrombosis, neurological deficits }\end{array}$ & Cervical LN & III & Unknown & Unknown \\
\hline 5 & $65 / \mathrm{M}$ & $\begin{array}{l}\text { Lytic lesion of left tibia, progressive } \\
\text { ankle pain }\end{array}$ & Bone (tibia) & I & $\begin{array}{l}\text { CHOP, Rituxan, } \\
\text { then radiation }\end{array}$ & Alive, in CR 10 months \\
\hline 6 & $40 / \mathrm{M}$ & Left axillary and infraclavicular mass & Axillary LN & II & CHOP, Rituxan & Alive, in CR 13 months \\
\hline 7 & $57 / F$ & Posterior cervical LAD & Cervical LN & $\mathrm{I}$ & $\begin{array}{l}\text { CHOP, Rituxan, } \\
\text { then radiation }\end{array}$ & Alive, in CR 17 months \\
\hline 8 & $80 / \mathrm{F}$ & $\begin{array}{l}\text { Multiple mediastinal LAD, } \\
\text { thrombocytopenia }\end{array}$ & $\begin{array}{l}\text { Mediastinal } \\
\text { LN }\end{array}$ & III & CHOP, Rituxan & Died of disease 8 months \\
\hline
\end{tabular}

CHOP, cyclophosphamide, vincristin, adriamycin, and prednisone; CR, complete remission; LAD, lymphadenopathy; LN, lymph node.

four females. All patients presented with de novo lymphoma manifesting as either lymphadenopathy (seven cases) or a lytic bone mass (1 case). None were reported to have either bone marrow or peripheral blood involvement, and their clinical stage was heterogeneous. Clinical follow-up information was available for five patients, all of whom had received a CHOP (cyclophosphamide, vincristin, adriamycin, and prednisone)-based chemotherapeutic regimen. Four patients were also treated with Rituxan, two of whom were subsequently given radiation therapy. Of these five patients, four are alive and in remission, whereas one died of disease at the time of completion of this study.

\section{Morphological Findings}

The histological appearances of the eight cases were similar. The cases with nodal presentation displayed near total effacement of the nodal architecture. In five cases, the neoplastic proliferation exhibited an entirely diffuse growth pattern (Figure 1a). In three cases, focal areas accounting for $\leq 10 \%$ of the neoplastic proliferation displayed a follicular growth pattern (Figure 1b). Variable numbers of scattered epithelioid histiocytes and/or tingible body macrophages were seen in most cases, which imparted a starry sky appearance focally (Figure 1c). The neoplastic cells were medium in size, that is, nuclear size intermediate between that of a small lymphocyte and macrophage. The nuclei were regularly round and contained finely dispersed chromatin and one to multiple small nucleoli; they were surrounded by poorly defined cytoplasm (Figure 1d). Numerous mitoses were noted (5-16 per high-power field). Significant necrosis was seen in only one case (case 8).

\section{Immunohistochemical Findings}

The results of immunohistochemical studies performed on each case are summarized in Table 2. In all cases, the neoplastic infiltrate was comprised of B-cells, based on their expression of CD20 (Figure 2a) and Pax-5. The tumor cells from all cases were also immunoreactive for the follicle center cell-associated antigens, CD10 (Figure 2b) and BCL6 (Figure 2c), and overexpressed the BCL2 protein (Figure 2d). In four of the cases, the neoplastic cells expressed MUM1 (two cases strongly). In none of the cases did the neoplastic cells express CYCLIN D1 (Figure 2e) or TdT (Figure 2f), nor did they overexpress the p53 oncoprotein (Figure 2g). Seven of the eight cases of blastoid diffuse B-cell lymphoma expressed CD43 (Figure 2h). Of these, one (case 6) was also CD7 positive (Figure 3a, b) and CD57 positive, and three other cases expressed one additional T-cell marker each (case 1: CD57; case 4: CD5; case 5: CD8) (Figure 3c, d). In only one case (case 8), were the neoplastic cells devoid of T-cell antigens. In keeping with their blastic qualities, the tumor cells were associated with a high proliferation rate $(80 \%$ or greater), based on semiquantitative determination of Ki-67 nuclear reactivity. In all cases, the proliferative pattern was diffuse or predominantly diffuse. CD21 allowed the demonstration of the presence of meshworks of follicular dendritic cells focally in three cases (the same cells expressed CD23 in only two cases).

\section{Polymerase Chain Reaction}

PCR was performed on all eight cases of blastoid diffuse B-cell lymphoma, of which DNA was amplifiable in six cases. All six cases showed clonal rearrangement of the immunoglobulin heavy chain gene, as shown by the framework 2 and/or framework 3 primers; none displayed rearrangement of the TCR- $\gamma$ gene (Table 3 ).

\section{Cytogenetic Analysis}

FISH analysis was attempted in all eight cases and was successful in five cases of blastoid diffuse B-cell lymphoma. These results are summarized in Table 3. 

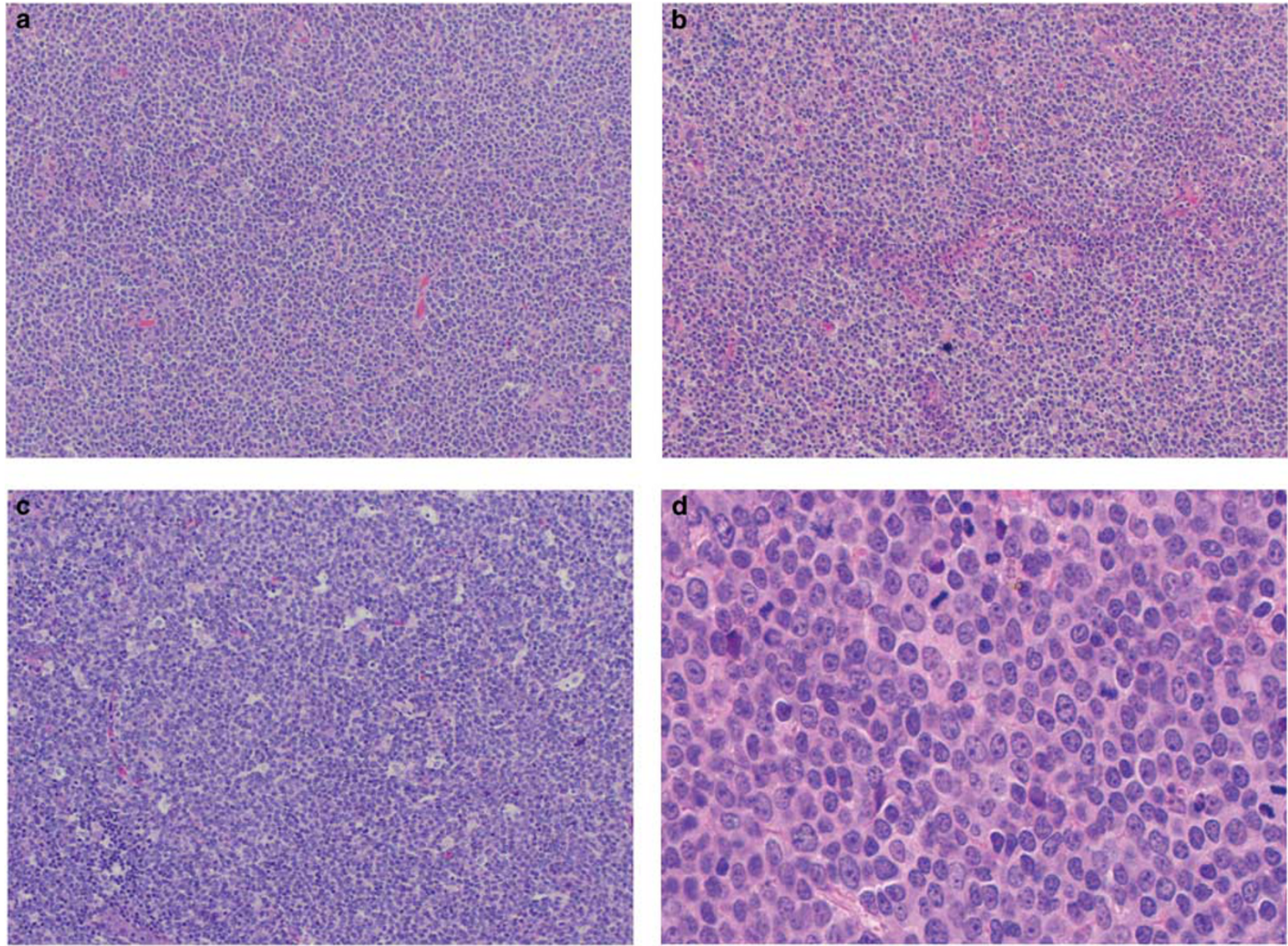

Figure 1 Morphological features of diffuse blastoid B-cell lymphomas. The architecture of this lymph node is effaced by an abnormal lymphoid proliferation with mostly diffuse $(\mathbf{a} ; \times 150)$, and only focal, vaguely nodular growth pattern $(\mathbf{b} ; \times 150)$. Scattered epithelioid histiocytes and/or tingible body macrophages are seen in most cases, which on low magnification impart a starry sky appearance $(\mathbf{c} ; \times 150)$. The tumor cells are medium-sized with round nuclei, finely dispersed chromatin, multiple small nucleoli, and high mitotic rate $(\mathbf{d} ; \times 600)$. These histological features are similar in all eight cases in this study.

Table 2 Immunophenotypic findings of eight cases of diffuse blastoid B-cell lymphoma

Case CD20 Pax-5 CD21 CD23 CD10 BCL2 BCL6 MUM-1 CD43 CD2 CD3 CD5 CD7 CD4 CD8 TIA-1 CD16 CD56 CD57 Ki67 p53 TdT CYCLIN D1 no.

\begin{tabular}{|c|c|c|c|c|c|c|c|c|c|c|c|c|c|c|c|c|c|c|c|c|c|c|c|}
\hline 1 & + & + & + & wk+ & + & + & + & + & + & - & - & - & - & - & - & - & - & - & wk+ & $>90 \%$ & - & - & - \\
\hline 2 & + & + & - & - & + & + & + & + & + & - & - & - & - & - & - & - & - & - & - & $90 \%$ & - & - & - \\
\hline 3 & + & + & + & - & + & + & + & - & + & - & - & - & - & - & - & - & - & - & - & $80 \%$ & - & - & - \\
\hline 4 & + & + & - & - & + & + & + & + & + & - & - & + & - & - & - & - & - & - & - & $>90 \%$ & - & - & - \\
\hline 5 & + & + & - & - & + & + & + & + & + & - & - & - & - & - & + & - & - & - & - & $>80 \%$ & - & - & - \\
\hline 6 & + & + & - & - & wk+ & + & + & - & + & - & - & - & + & - & - & - & - & - & + & $>90 \%$ & - & - & - \\
\hline 7 & + & + & + & + & + & + & + & - & + & - & - & - & - & - & - & - & - & - & - & $>90 \%$ & - & - & - \\
\hline 8 & + & + & ND & ND & wk+ & + & + & - & - & - & - & - & - & - & - & - & - & - & - & $>90 \%$ & - & - & - \\
\hline
\end{tabular}

ND, not done; wk+, weakly positive.

None of the five cases showed $\mathrm{t}(14 ; 18)(\mathrm{q} 32 ; \mathrm{q} 21)$, based on the lack of IgH-BCL2 fusion signals. However, increased copy number of the BCL2 gene was observed in four cases (Figure 4a), which resulted from an increased copy number of chromosome 18, as shown by the centromeric CEP 18 probe; the copy number ranged from three to six (Figure 4b). Two intact green signals, representing two copies of
IgH gene, were seen in all cases. Four cases showed abnormalities involving the BCL6 gene: these included loss of one allele (two cases), gain of one allele (one case), and rearrangement (one case). All five cases showed deletion of the $13 q 14$ region, whereas four cases showed monosomy 7. None of the cases showed a $M Y C$ gene rearrangement; however, loss of one allele was observed in four cases. 

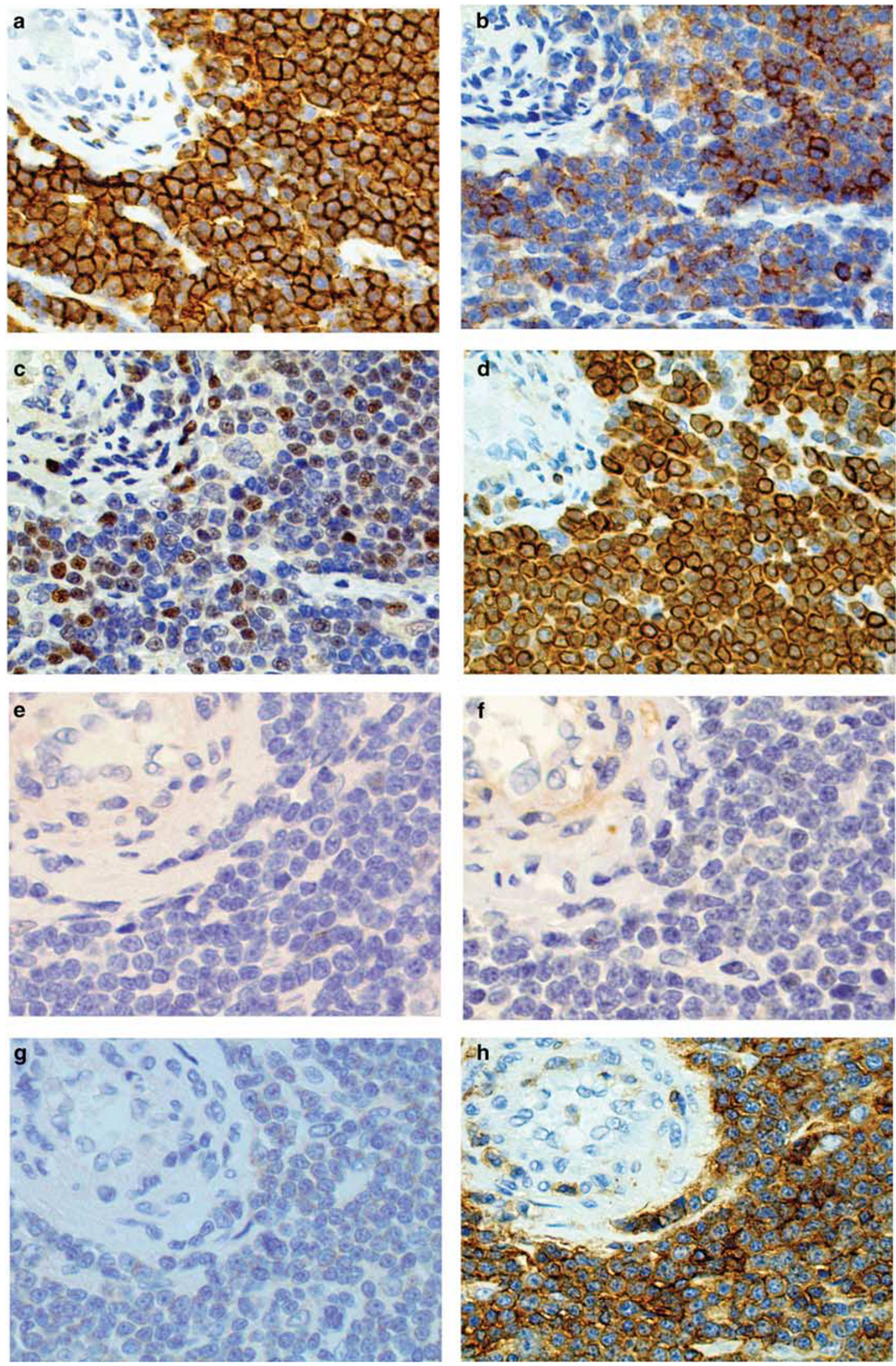

Figure 2 Immunophenotypic features of diffuse blastoid B-cell lymphomas. The neoplastic cells in all eight cases are strongly CD20 positive (a), express the follicle center cell-associated antigens CD10 (b) and BCL6 (c), and strongly overexpress BCL2 (d). However, immunostaining for CYCLIN D1 (e) and TdT (f) are negative, and the tumor cells do not overexpress the p53 oncoprotein (g). The vast majority of the cases show strong immunoreactivity for CD43 (h). Photographs were taken from case no. 4. 

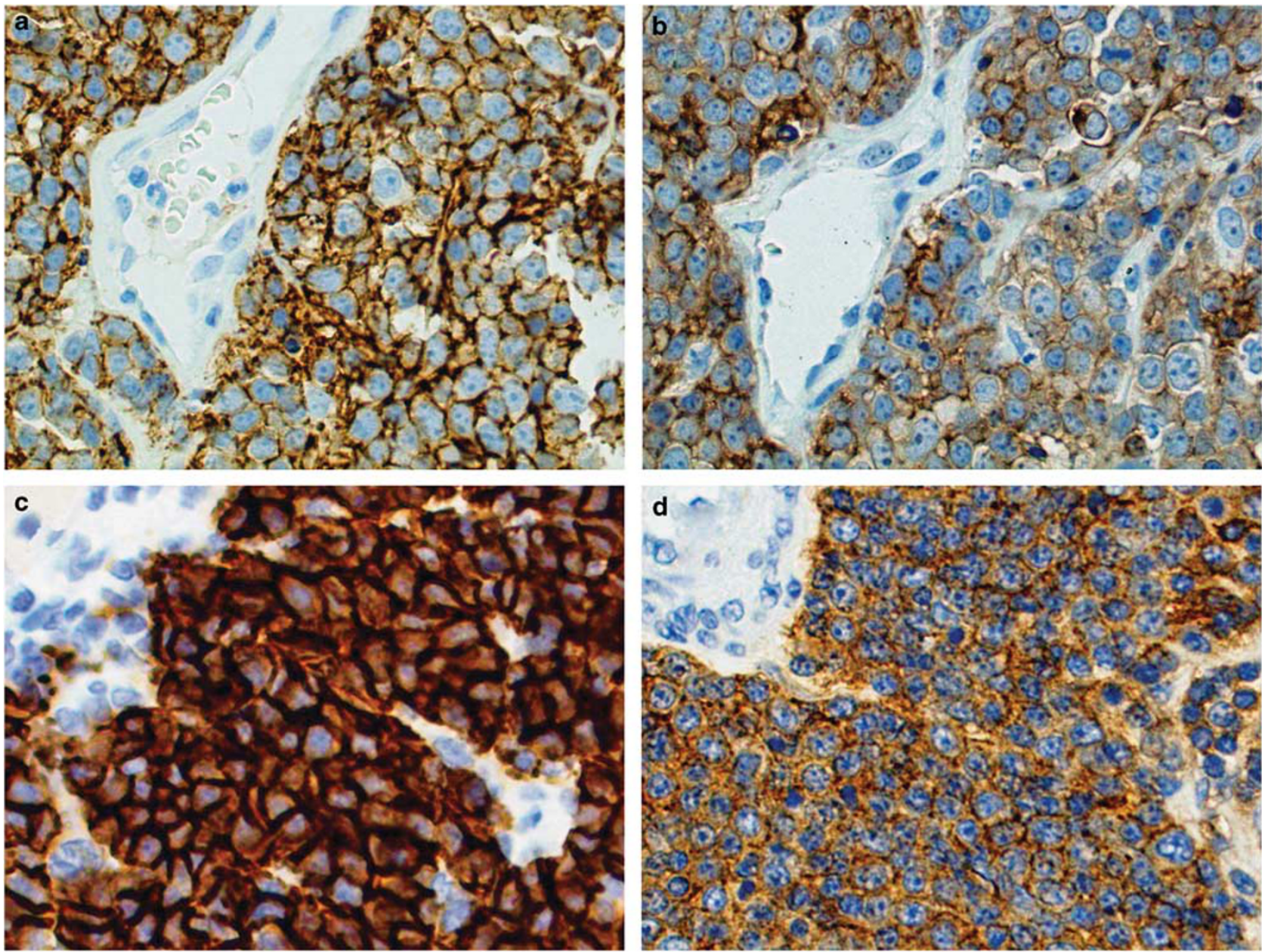

Figure 3 Aberrant T-cell-associated antigen expression. Although the B-cell origin of the tumor cells is shown by strong CD20 (a, c) expression, case no. 6 also shows aberrant expression for both CD7 (b) and CD57 (not shown), whereas case no. 5 also expresses CD8 (d).

Table 3 Summary of PCR and fluorescence in situ hybridization results

\begin{tabular}{|c|c|c|c|c|c|c|c|c|}
\hline \multirow[t]{2}{*}{ Case no. } & \multicolumn{2}{|c|}{ PCR } & \multicolumn{6}{|l|}{ FISH } \\
\hline & $J H$ & $T \gamma$ & CEP7 & $L S I 13 q$ & $B C L 6$ & $M Y C$ & $t(14 ; 18)$ & CEP18 \\
\hline 1 & $\mathrm{R}$ & G & Normal & $\operatorname{del}(13)(q 14)$ & Allele loss & Allelic loss & - & Normal \\
\hline 2 & $\mathrm{R}$ & G & $\operatorname{del}(7)$ & $\operatorname{del}(13)(q 14)$ & Allele loss & Allelic loss & - & Four to six copies \\
\hline 3 & $\mathrm{R}$ & G & $\operatorname{del}(7)$ & $\operatorname{del}(13)(q 14)$ & Normal & Allelic loss & - & Four to six copies \\
\hline 4 & $\mathrm{R}$ & G & $\operatorname{del}(7)$ & $\operatorname{del}(13)(q 14)$ & $\mathrm{R}$ & Normal & - & Four to five copies \\
\hline 6 & $\mathrm{R}$ & G & NS & NS & NS & NS & NS & NS \\
\hline 7 & $\mathrm{R}$ & G & $\operatorname{del}(7)$ & $\operatorname{del}(13)(q 14)$ & Allele gain & Allelic loss & - & Three copies \\
\hline
\end{tabular}

G, germline; NS: not successful; R, rearranged (detected by either framework 3 and/or framework 2 primers). DNA for cases 5 and 8 was not amplifiable.

In summary, absence of $\mathrm{t}(14 ; 18)(\mathrm{q} 32 ; \mathrm{q} 21)$ (all five cases), increased the copy number of $B C L 2 /$ chromosome 18 (four cases), BCL6 abnormalities (four cases), del(13)(q14) (all five cases), monosomy 7 (four cases), and loss of one MYC allele (four cases) were observed in our series of blastoid diffuse B-cell lymphomas.

\section{Discussion}

We report eight cases of a histologically aggressive variant of B-cell lymphoma with diffuse or predominantly diffuse pattern and blastic morphology that possesses characteristic pathological features. Four of the five patients with clinical follow-up data 

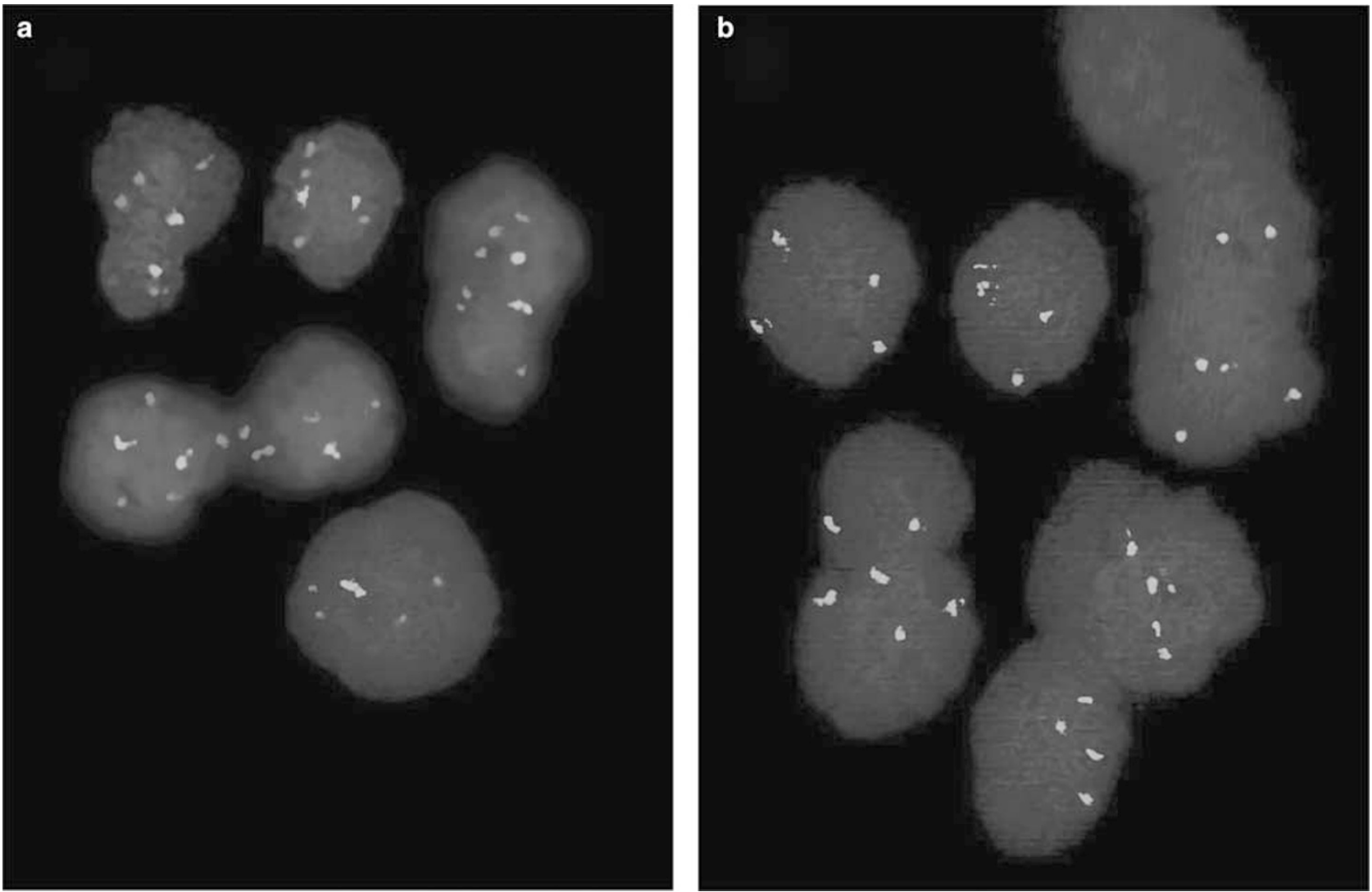

Figure 4 Interphase fluorescence in situ hybridization. Increased copy number of BCL2 is shown by increased number of red signals (color version appears online) (a), whereas two intact green signals representing two copies of IgH gene are observed; probes used were LSI IgH (spectrum green)/BCL2 (spectrum orange). CEP 18 spectrum green-labeled probe shows increased copy number of chromosome (b).

responded well to the treatment and achieved clinical remission, whereas one died of disease. Histologically, these neoplasms are composed of tumor cells of medium size with blastic morphology, a diffuse or predominantly diffuse growth pattern, expression of the follicle center cell-associated antigens CD10, BCL6, and BCL2, and aberrant expression of one or more T-cell-associated antigens. Furthermore, they are associated with a high proliferation rate, and frequently show cytogenetic abnormalities, involving the BCL6 gene, monosomy 7 , or deletion of the 13q14 region. Despite their follicle center cell characteristics, all these neoplasms lack the $t(14 ; 18)$ translocation, but instead often show an increased copy number of chromosome 18 that could possibly account for BCL2 overexpression. Gain of chromosome 18q21 has been shown to be a frequent genetic abnormality in cases of t(14;18)-negative follicular lymphoma ${ }^{5}$ and of diffuse large B-cell lymphoma. ${ }^{6}$ Although some of the features of diffuse blastoid B-cell lymphoma overlap with those of diffuse follicular lymphoma, ${ }^{1,7}$ their cytological characteristics, such as the finely dispersed nuclear chromatin in nuclei lacking evident nucleoli and poorly defined cytoplasm, the expression of CD43, and their high proliferation rate, distinguish them from diffuse follicular lym- phoma. The morphology and immunophenotype, and above all the lack of $M Y C$ rearrangement exclude Burkitt and Burkitt-like lymphoma. It is very difficult, based on cytology alone, to distinguish the tumor cells of diffuse blastoid B-cell lymphoma from those of lymphoblastic lymphoma or the blastic/blastoid variant of mantle cell lymphoma. However, lymphoblastic lymphoma and the blastoid variant of mantle cell lymphoma can be excluded in our cases by their lack of TdT and CYCLIN D1 expression, respectively. In addition, the immunophenotype of diffuse blastoid B-cell lymphoma is distinctly different from that seen in cases of mantle cell lymphoma. This is particularly important in view of the possibility of CYCLIN D1-negative mantle cell lymphoma, a rare but nevertheless well-documented occurrence. ${ }^{8}$ Such a diagnostic possibility could have been considered in case 4, particularly in view of its positivity with CD5. However, the presence, in this case, of positivity with CD10, BCL6, and MUM1 tend to exclude blastoid mantle cell lymphoma as an alternative diagnostic possibility.

All the diffuse blastoid B-cell lymphomas in our study expressed the follicle center cell-associated antigens, CD10 and BCL6. Although neither CD10 nor BCL6 is per se a specific marker for follicular 
lymphoma, as their expression has been reported in a subset of T-cell non-Hodgkin's lymphomas, ${ }^{9,10}$ their simultaneous expression by a B-cell neoplasm is generally accepted to be consistent with a follicle center cell origin. This is supported by findings of DNA microarray and tissue array studies, in which expression of both CD10 and BCL6 was found to be closely associated with diffuse large B-cell lymphomas with a germinal center B-cell-like gene expression profile. ${ }^{11,12}$ Expression of MUM1, which was seen in a proportion of our cases, is also consistent with the interpretation that these blastoid cases share a common derivation with high-grade follicular lymphoma, which are also frequently MUM1 positive. ${ }^{13,14} \mathrm{~A}$ most noticeable finding in this series is the lack of a $t(14 ; 18)$ translocation. Although considered as the hallmark of follicular lymphoma, the negativity for $t(14 ; 18)$, however, does not by itself exclude a diagnosis of follicular lymphoma. Approximately 15-25\% of otherwise typical cases of low-grade follicular lymphoma are negative for $\mathrm{t}(14 ; 18) .^{7,15,16}$ Moreover, follicular lymphoma grade 3 , particularly the 3B subset in which the follicles are entirely composed of large cells, are also, as a rule, $\mathrm{t}(14 ; 18)$ negative. ${ }^{17-19}$ Furthermore, the existence of a $t(14 ; 18)$-negative subset of diffuse follicular lymphoma has been recently well documented. ${ }^{7}$ In view of the observed morphological, immunohistochemical, and molecular results, our cases, therefore, most likely correspond to a histologically aggressive (that is, blastoid) variant of $\mathrm{t}(14 ; 18)$-negative follicular lymphoma with a predominant diffuse proliferative pattern.

B-cell non-Hodgkin's lymphomas generally lack aberrant expression of T-cell antigens with the exception of CD5 and CD43. ${ }^{18-20}$ Although CD5 expression is characteristic of chronic lymphocytic leukemia/small lymphocytic lymphoma and mantle cell lymphoma, it is rarely observed in other categories of B-cell non-Hodgkin's lymphoma. ${ }^{21-23}$ CD43 expression, although relatively common in several subtypes of B-cell non-Hodgkin's lymphoma, is unusual in follicular lymphoma $(3 \%){ }^{24}$ However, CD43 expression is detected relatively often in cases of high-grade follicular lymphoma both with and without diffuse areas. ${ }^{1}$ Expression of T-cell antigens other than CD5 and CD43 in B-cell non-Hodgkin's lymphomas is exceptional. ${ }^{20,25,26}$ The diffuse blastoid B-cell lymphomas in our study were almost always CD43 positive (seven of eight cases); four of these cases also expressed one or two additional T-cell-associated markers: CD5 (case 4), CD8 (case 5), CD57 (case 1), and both CD7 and CD57 (case 6). This T-cell-antigen reactivity seems to represent aberrant expression, as all six cases with successful DNA amplification showed clonal rearrangement of the immunoglobulin heavy chain gene, but not of the TCR- $\gamma$ chain gene. The prognostic significance of T-cell antigen expression in B-cell non-Hodgkin's lymphomas remains somewhat controversial. CD5 expression in some series of extranodal marginal zone lymphoma ${ }^{27,28}$ and $d e$ novo diffuse large B-cell lymphoma ${ }^{22,23,29}$ has been associated with a clinically aggressive course and tendency for dissemination, although other studies have failed to support these findings. ${ }^{30}$ Only one of five patients with clinical follow-up data in our study died of disease. Interestingly, but perhaps coincidentally, this is the only case without T-cell antigen expression.

Several cytogenetic abnormalities were frequently detected in our cases of blastoid diffuse B-cell lymphomas. In the absence of fresh tissue that could be used for conventional cytogenetics, as most of our cases were consultation material, we evaluated our cases for chromosomal abnormalities commonly associated with high-grade B-cell morphology, that is, trisomy 7, $\operatorname{del}(13)$ (q14), and $M Y C$ rearrangement, as well as $\mathrm{t}(14 ; 18)$ and $B C L 6$ rearrangements by interphase FISH on paraffin tissue sections.

Trisomy 7 is a frequent finding (25\%) in follicular lymphomas with $\mathrm{t}(14 ; 18)$, in which it has been associated with high-grade morphology, a diffuse growth pattern, and an aggressive disease course. ${ }^{31-34}$ Gain of chromosome 7 is also frequently detected in diffuse large B-cell lymphoma, especially in those that transformed from low-grade follicular lymphomas. ${ }^{35}$ Instead of a gain, we detected a loss of chromosome 7 in four of five cases of diffuse blastoid B-cell lymphoma. Monosomy 7 is common in myelodysplastic syndrome and acute myeloid leukemia, particularly in therapy-related cases, in which it is considered as a poor prognostic factor. ${ }^{36}$ Monosomy 7 also may be occasionally seen in acute lymphoblastic lymphoma/leukemia, but is not particularly associated with other subtypes of nonHodgkin's lymphoma. Therefore, the presence of monosomy 7 is a unique finding; however, its significance in our cases, if any, is not clear.

Deletion of 13q14 is found quite commonly in hematological malignancies. It is the most frequent genetic aberration in chronic lymphocytic leukemia/ small lymphocytic lymphoma, ${ }^{37}$ but has also been documented in multiple myeloma, ${ }^{38}$ and in nonhematological neoplasms of the head and neck ${ }^{39}$ and prostate. ${ }^{40}$ Although del(13)(q14) is associated with longer survival in chronic lymphocytic leukemia/ small lymphocytic lymphoma, ${ }^{41}$ it has been reported to predict an unfavorable outcome after chemotherapy in multiple myeloma. ${ }^{42} \operatorname{del}(13)(q 14)$ has been associated with higher grade histology and is thought to represent a late cytogenetic event in follicular lymphomas. ${ }^{34,43}$ We have shown this event in all five evaluable cases of diffuse blastoid B-cell lymphoma, but could not determine its prognostic significance.

Abnormalities of the MYC gene, although characteristic of Burkitt lymphoma, have also been documented in diffuse large B-cell lymphoma, especially among those occurring in extranodal sites. ${ }^{44}$ In addition, a small subset of follicular lymphoma, along with $\mathrm{t}(14 ; 18)(\mathrm{q} 32 ; 21)$, have a 
Burkitt-type translocation involving $8 \mathrm{q} 24$, that is, $\mathrm{t}(8 ; 14)(\mathrm{q} 24 ; \mathrm{q} 32), \mathrm{t}(8 ; 22)(\mathrm{q} 24 ; \mathrm{q} 11)$, or $\mathrm{t}(2 ; 8)(\mathrm{q} 12 ; \mathrm{q} 24)$; these 'double hit' cases are associated with blastic morphology, an aggressive disease course, and short survival. ${ }^{34,45}$ We did not detect $M Y C$ translocation, but rather found a loss of one $M Y C$ allele in four of our five cases, a feature which distinguishes diffuse blastoid B-cell lymphomas from the above mentioned cases of follicular lymphoma.

Rearrangement of the BCL 6 gene is an important chromosomal aberration in B-cell lymphomagenesis. The translocation at 3q27 may involve the $\mathrm{IgH}$ locus at $14 q 32$, but may also involve various other chromosomes, for example, $\mathrm{t}(3 ; 22)$ and $\mathrm{t}(2 ; 3)$, resulting in deregulation of the BCL 6 gene located at this breakpoint. ${ }^{46,47}$ BCL6 rearrangement is seen in $30-40 \%$ of diffuse large B-cell lymphoma, but in only $6-14 \%$ of follicular lymphoma. Among the latter group, it is particularly common in cases of grade 3B follicular lymphoma, with the highest frequency reported in cases associated with diffuse areas. Our results are, therefore, consistent with a follicular center cell-derived lymphoma, and suggest strong similarity to cases of $3 \mathrm{~B}$ follicular lymphoma, although with a diffuse growth pattern and blastoid morphology.

Among the cytogenetic alterations that we have evaluated, possibly the most interesting is the one that was not detected. Remarkably, all five cases with successful FISH lacked the $B C L 2 / I g H(t(14 ; 18))$ rearrangement, and yet expressed the follicle center cell-associated markers, CD10 and BCL6, and strongly overexpressed the BCL2 protein. There was no evidence of a variant translocation involving IgH and another partner chromosome, as two intact IgH signals were observed in all cases by interphase FISH analysis. On the other hand, four of five cases showed multiple copies (three to six) of chromosome 18. In the past few years, $t(14 ; 18)$ negative follicular lymphoma has been well characterized..$^{5-7,16}$ This follicular lymphoma subset includes two main subtypes, ${ }^{16}$ the first lacking BCL2 overexpression but having $t(3 ; 14)$ or another 3q27 structural alteration, indicating that BCL6 deregulation may represent an alternate molecular mechanism leading to the development of follicular lymphoma. The second group shows strong BCL2 overexpression and extra copies of chromosome 18. Our cases bear close resemblance to this second group, in which BCL2 overexpression was not likely the result of a $B C L 2 / I g H$ translocation but rather due to an increased dosage effect. This might represent the mechanism of neoplastic transformation of blastoid diffuse B-cell lymphomas from germinal center cells, along a molecular pathway distinct from that of classic follicular lymphoma. In case 1, which showed a normal copy number of chromosome 18, another undefined molecular mechanism might have given rise to BCL2 deregulation.

Although there are similarities between our cases of diffuse blastoid B-cell lymphomas and the rare cases of follicular lymphoma in blastic/blastoid transformation reported by Natkunam et al., ${ }^{48}$ namely, the blast-like cytology, focal presence of follicle-like structures, and expression of follicle center cell markers, the differences are much greater. In contrast with our cases of diffuse blastoid B-cell lymphomas, all those cases were preceded by a follicular lymphoma, were predominantly follicular in pattern, and all had $t(14 ; 18)$, as shown either by cytogenetics or by PCR. However, in view of their similarities, one cannot exclude that at least a proportion of our cases may represent a $t(14 ; 18)-$ negative diffuse counterpart of blastoid follicular lymphoma.

In conclusion, the eight cases of diffuse blastoid B-cell lymphoma evaluated in this study are de novo diffuse B-cell lymphomas with blastoid morphology that need to be differentiated from other hematological malignancies with blastoid or blastic features. They seem to be of follicle center cell origin, but lack t(14;18), show CD43 antigen expression, have extra copies of chromosome 18, and possess other cytogenetic abnormalities. This combination of features suggests that diffuse blastoid B-cell lymphomas may represent a distinct variant within the spectrum of $\mathrm{t}(14 ; 18)$-negative follicular lymphoma. In this context, the presence of high proliferative activity, CD43 expression, and not uncommon MUM1 expression would suggest a similarity to cases of grade 3 follicular lymphoma, a subset which also often lacks a $\mathrm{t}(14 ; 18)$ translocation. Recognition of these cases by other investigators and further study of large number of cases of this unusual histological variant should help to further elucidate their pathogenesis and their natural history.

\section{Disclosure/conflict of interest}

The authors declare no conflict of interest.

\section{References}

1 Swerdlow SH, Campo E, Harris NL et al (eds). WHO Classification Of Tumors Of The Haematopoietic And Lymphoid Tissues. IARC: Lyon, 2008.

2 Wright DK, Manos MM. Sample preparation from paraffin-embedded tissues. In: Innis MA, Gelfand DH, Sninsky JJ. et al. (eds) PCR Protocols: A Guide To Methods And Applications 1990, Academic Press: San Diego.

3 Diss TC, Peng H, Wotherspoon AC, et al. Detection of monoclonality in low-grade B-cell lymphomas using the polymerase chain reaction is dependent on primer selection and lymphoma type. J Pathol 1993;169: 291-295.

4 McCarthy KP, Sloane JP, Kabarowski JH, et al. A simplified method of detection of clonal rearrangements of the T-cell receptor-gamma chain gene. Diagn Mol Pathol 1992;1:173-179.

5 Nanjangud G, Rao PH, Teruya-Feldstein J, et al. Molecular cytogenetic analysis of follicular lymphoma 
(FL) provides detailed characterization of chromosomal instability associated with the $t(14 ; 18)(q 32 ; q 21)$ positive and negative subsets and histologic progression. Cytogenet Genome Res 2007;118:337-344.

6 Dierlamm J, Murga Penas EM, Bentink S, et al. Molecular mechanisms in malignant lymphomas'. Gain of chromosome region $18 \mathrm{q} 21$ including the MALT1 gene is associated with the activated B-celllike gene expression subtype and increased BCL2 gene dosage and protein expression in diffuse large B-cell lymphoma. Haematologica 2008;93:688-696.

7 Katzenberger T, Kalla J, Leich E, et al. A distinctive subtype of $\mathrm{t}(14 ; 18)$ negative nodal follicular nonHodgkin lymphoma characterized by a predominantly diffuse growth pattern and deletions in the chromosomal region 1p36. Blood 2009;113:1053-1061.

$8 \mathrm{Fu} \mathrm{K}$, Weisenburger DD, Greiner TC, et al. Lymphoma/ leukemia molecular profiling project. Cyclin D1-negative mantle cell lymphoma: a clinicopathologic study based on gene expression profiling. Blood 2005;106: 4315-4321.

9 Attygalle A, Al Jehani R, Diss TC, et al. Neoplastic T cells in angioimmunoblastic T-cell lymphoma express CD10. Blood 2002;99:627-633.

10 de Leval L, Savilo E, Longtine J, et al. Peripheral T-cell lymphoma with follicular involvement and a CD4+/ bcl-6+ phenotype. Am J Surg Pathol 2001;25:395-400.

11 Alizadeh AA, Eisen MB, Davis RE, et al. Distinct types of diffuse large B-cell lymphoma identified by gene expression profiling. Nature 2000;403:503-511.

12 Hans CP, Weisenburger DD, Greiner TC, et al. Confirmation of the molecular classification of diffuse large B-cell lymphoma by immunohistochemistry using a tissue microarray. Blood 2004;103:275-282.

13 Naresh KN. MUM1 expression dichotomises follicular lymphoma into predominantly, MUM1-negative lowgrade and MUM1-positive high-grade subtypes. Haematologica 2007;92:267-268.

14 Keller CE, Nandula S, Fisher J, et al. The spectrum of B-cell non-Hodgkin lymphomas with dual IgH-BCL2 and BCL6 translocations. Am J Clin Pathol 2008;130: 193-201.

15 Karube K, Guo Y, Suzumiya J, et al. CD10-MUM1+ follicular lymphoma lacks BCL2 gene translocation and shows characteristic biologic and clinical features. Blood 2007;109:3076-3079.

16 Horsman DE, Okamoto I, Ludkovski O, et al. Follicular lymphoma lacking the $\mathrm{t}(14 ; 18)(\mathrm{q} 32 ; \mathrm{q} 21)$ : identification of two disease subtypes. Br J Haematol 2003;120: 424-433.

17 Ott G, Katzenberger T, Lohr A, et al. Cytomorphologic, immunohistochemical, and cytogenetic profiles of follicular lymphoma: 2 types of follicular lymphoma grade 3. Blood 2002;99:3806-3812.

18 Katzenberger $\mathrm{T}$, Ott G, Klein $\mathrm{T}$, et al. Cytogenetic alterations affecting BCL6 are predominantly found in follicular lymphomas grade $3 \mathrm{~B}$ with a diffuse large B-cell component. Am J Pathol 2004;165:481-490.

19 Bosga-Bouwer AG, van den Berg A, Haralambieva E, et al. Molecular, cytogenetic, and immunophenotypic characterization of follicular lymphoma grade 3B; a separate entity or part of the spectrum of diffuse large B-cell lymphoma or follicular lymphoma? Hum Pathol 2006;37:528-533.

20 Kaleem Z, White G, Zutter MM. Aberrant expression of T-cell-associated antigens on B-cell non-Hodgkin lymphomas. Am J Clin Pathol 2001;115:396-403.
21 Matolcsy A, Chadburn A, Knowles DM. De novo CD5positive and Richter's syndrome-associated diffuse large $\mathrm{B}$ cell lymphomas are genotypically distinct. Am J Pathol 1995;147:207-216.

22 Harada S, Suzuki R, Uehira K, et al. Molecular and immunological dissection of diffuse large B cell lymphoma: CD5+, and CD5- with CD10+ groups may constitute clinically relevant subtypes. Leukemia 1999;13:1441-1447.

23 Yamaguchi M, Ohno T, Oka K, et al. De novo CD5positive diffuse large B-cell lymphoma: clinical characteristics and therapeutic outcome. Br J Haematol 1999;105:1133-1139.

24 Lai R, Weiss LM, Chang KL, et al. Frequency of CD43 expression in non-Hodgkin lymphoma. A survey of 742 cases and further characterization of rare CD43+ follicular lymphomas. Am J Clin Pathol 1999;111: 488-494.

25 Kingma DW, Imus P, Xie XY, et al. CD2 is expressed by a subpopulation of normal B cells and is frequently present in mature B-cell neoplasms. Cytometry 2002; 50:243-248.

26 Inaba T, Shimazaki C, Sumikuma T, et al. Expression of T-cell-associated antigens in B-cell non-Hodgkin's lymphoma. Br J Haematol 2000;109:592-599.

27 Ferry JA, Yang WI, Zukerberg LR, et al. CD5+ extranodal marginal zone B-cell (MALT) lymphoma. A low grade neoplasm with a propensity for bone marrow involvement and relapse. Am J Clin Pathol 1996;105:31-37.

28 Wenzel C, Dieckmann K, Fiebiger W, et al. CD5 expression in a lymphoma of the mucosa-associated lymphoid tissue (MALT)-type as a marker for early dissemination and aggressive clinical behaviour. Leuk Lymphoma 2001;42:823-829.

29 Dong HY, Gorczyca W, Liu Z, et al. B-cell lymphomas with coexpression of CD5 and CD10. Am J Clin Pathol 2003;119:218-230.

30 Ballesteros E, Osborne BM, Matsushima AY. CD5+ low-grade marginal zone B-cell lymphomas with localized presentation. Am J Surg Pathol 1998;22: 201-207.

31 Horsman DE, Connors JM, Pantzar T, et al. Analysis of secondary chromosomal alterations in 165 cases of follicular lymphoma with $\mathrm{t}(14 ; 18)$. Genes Chromosomes Cancer 2001;30:375-382.

32 Knutsen T. Cytogenetic mechanisms in the pathogenesis and progression of follicular lymphoma. Cancer Surv 1997;30:163-192.

33 Armitage JO, Sanger WG, Weisenburger DD, et al. Correlation of secondary cytogenetic abnormalities with histologic appearance in non-Hodgkin's lymphomas bearing $t(14 ; 18)(q 32 ; q 21)$. J Natl Cancer Inst 1988;80:576-580.

34 Mohamed AN, Palutke M, Eisenberg L, et al. Chromosomal analyses of 52 cases of follicular lymphoma with $\mathrm{t}(14 ; 18)$, including blastic/blastoid variant. Cancer Genet Cytogenet 2001;126:45-51.

35 Boonstra R, Bosga-Bouwer A, Mastik $\mathrm{M}$, et al. Identification of chromosomal copy number changes associated with transformation of follicular lymphoma to diffuse large B-cell lymphoma. Hum Pathol 2003; 34:915-923.

36 Mauritzson N, Albin M, Rylander L, et al. Pooled analysis of clinical and cytogenetic features in treatment-related and de novo adult acute myeloid leukemia and myelodysplastic syndromes based on a 
consecutive series of 761 patients analyzed 1976-1993 and on 5098 unselected cases reported in the literature 1974-2001. Leukemia 2002;16:2366-2378.

37 Dohner H, Stilgenbauer S, Dohner K, et al. Chromosome aberrations in B-cell chronic lymphocytic leukemia: reassessment based on molecular cytogenetic analysis. J Mol Med 1999;77:266-281.

38 Shaughnessy Jr J, Tian E, Sawyer J, et al. High incidence of chromosome 13 deletion in multiple myeloma detected by multiprobe interphase FISH. Blood 2000;96:1505-1511.

39 Maestro R, Piccinin S, Doglioni C, et al. Chromosome $13 \mathrm{q}$ deletion mapping in head and neck squamous cell carcinomas: identification of two distinct regions of preferential loss. Cancer Res 1996;56: 1146-1150.

40 Chen C, Frierson Jr HF, Haggerty PF, et al. An 800-kb region of deletion at $13 q 14$ in human prostate and other carcinomas. Genomics 2001;77:135-144.

41 Dohner H, Stilgenbauer S, Fischer K, et al. Cytogenetic and molecular cytogenetic analysis of B cell chronic lymphocytic leukemia: specific chromosome aberrations identify prognostic subgroups of patients and point to loci of candidate genes. Leukemia 1997; 11(Suppl 2):S19-S24.

42 Shaughnessy Jr J, Tian E, Sawyer J, et al. Prognostic impact of cytogenetic and interphase fluorescence in situ hybridization-defined chromosome 13 deletion in multiple myeloma: early results of total therapy II. Br J Haematol 2003;120:44-52.

43 Hoglund M, Sehn L, Connors JM, et al. Identification of cytogenetic subgroups and karyotypic pathways of clonal evolution in follicular lymphomas. Genes Chromosomes Cancer 2004;39:195-204.

44 Kramer $\mathrm{MHH}$, Hermans J, Wijburg E, et al. Clinical relevance of BCL2, BCL6, and MYC rearrangements in diffuse large b-cell lymphoma. Blood 1998;92: 3152-3162.

45 Karsan A, Gascoyne RD, Coupland RW, et al. Combination of $\mathrm{t}(14 ; 18)$ and a Burkitt's type translocation in B-cell malignancies. Leuk Lymphoma 1993;10: 433-441.

46 Ye BH, Rao PH, Chaganti RS, et al. Cloning of bcl-6, the locus involved in chromosome translocations affecting band 3q27 in B-cell lymphoma. Cancer Res 1993;53: 2732-2735.

47 Kerckaert JP, Deweindt C, Tilly H, et al. LAZ3, a novel zinc-finger encoding gene, is disrupted by recurring chromosome 3q27 translocations in human lymphomas. Nat Genet 1993;5:66-70.

48 Natkunam Y, Warnke RA, Zehnder JL, et al. Blastic/ blastoid transformation of follicular lymphoma: immunohistologic and molecular analyses of five cases. Am J Surg Pathol 2000;24:525-534. 